\title{
La Moda elegante ilustrada y el Correo de las Damas, dos publicaciones especializadas en moda en el siglo XIX
}

\section{La Moda elegante ilustrada and Correo de las Damas. Two Fashion Magazines in the XIX Century}

\author{
Laura González Díez, profesora de diseño gráfico. Universidad CEU San Pablo \\ Pedro Pérez Cuadrado, profesor de diseño de la información. Universidad Rey Juan Carlos
}

Recibido: 16-XII-2008 - Aceptado: 2-III-2009

Resumen:

A partir de 1829 se produce en España una proliferación de publicaciones especializadas en moda. El desarrollo de las comunicaciones y la transformación de las máquinas de imprenta que propició la Revolución Industrial ocasionó en toda Europa importantes cambios que van a afectar a los contenidos y al diseño de las publicaciones periódicas, tanto a los diarios como a las revistas ilustradas, dentro de las cuales tenemos que incluir las especializadas en moda, en un momento en que ésta se convirtió en un símbolo de clase y en un modo de manifestar el estatus social. El objetivo del presente artículo es analizar el aspecto formal de las publicaciones especializadas en moda del siglo XIX en nuestro país (fundamentalmente en el Correo de las Damas, de 1833 y La Moda elegante ilustrada, de 1841), centrándonos en su diseño y atendiendo a la utilización que hacen de la tipografía, el color y la imagen, y que establecen ya unos códigos visuales que se mantienen en la actualidad.

Palabras clave:

Revista, moda, diseño, figurín, tipografía, siglo XIX, La Moda elegante, Correo de las Damas

Abstract:

During the XIX century, from 1829 and on, Spain suffers a specialized fashion publications proliferation. The development in communications and the transformation of printing machines, which made possible the Second Industrial Revolution, caused important changes which would affect the content and design of periodic publications. The daily publications development coincides with the one experienced by illustrated magazines, in which we should include those specialized on fashion. The birth of the Second Industrial Revolution not only transformed the world of communications but the international relations and business trade. In this sense, fashion turned to be a symbol of social standing and a way of showing social status. The aim of this communication is to analyze the formal and graphic aspects of specialized fashion publications during the XIX century in our country (Correo de las Damas, from 1833 and La Moda elegante, from 1841), focusing specially on the publications design attending to those elements such as typography, image and colour, which established visual codes that still remain nowadays.

Key words:

Magazine, fashion, desing, drawings, tipography, XIX Century, La Moda elegante, Correo de las Damas 


\section{Introducción}

Aunque las revistas sobre moda existen desde el siglo XVIII, no será hasta la segunda década del siglo XIX cuando se produzca el despegue hacia un público masivo. Prueba de ello es que -por ejemplo- entre 1829 y 1868, en España se lanzaron más de treinta cabeceras especializadas en moda, periódicos o revistas dirigidos a las mujeres de la alta sociedad y la burguesía que les proporcionaban información sobre moda, cultura, literatura o aspectos domésticos, entre otros. Si bien hay que tener en cuenta que muchas de estas publicaciones tuvieron una vida efímera y que nuestro país siempre fue a remolque de otros países europeos -Inglaterra llegará a mantener 24 publicaciones especializadas en moda en 1880 (Smith, 1979: 127)podemos asegurar que es en ese momento cuando la moda, en el sentido moderno del término, entra en escena, convirtiéndose en un símbolo de clase y en un modo de manifestar el estatus social.

Al mismo tiempo, la Revolución Industrial favoreció el desarrollo de las comunicaciones y la transformación de las máquinas de imprenta en toda Europa, lo que unido a una mayor libertad de prensa supuso unos cambios muy importantes que afectaron tanto a los contenidos como al diseño de las publicaciones periódicas. Se producirá un desarrollo de la prensa en general y de las revistas ilustradas en particular, entre las que se incluyen las especializadas en moda destinadas al público femenino. En Europa debemos resaltar, antes de finalizar el siglo XVIII, el Journal des Femmes (1759) o Lady Journal (1775), en Francia, y el Giornale della donna galante ed erudita (1780), en Italia.

No será el caso de España en las primeras etapas de este tipo de prensa donde "el tema de la moda femenina -tal y como apuntan algunos autores- no aparece en La Pensadora Gaditana (1763) sino, como en tantas otras publicaciones ilustradas [...], para criticar a las (y los) que se sometían a su tiranía e insistir en los aspectos morales de la indecencia, el lujo excesivo y la ridícula imitación de lo francés” (Seoane y Sáiz, 2007: 52).

Hay que citar, sin embargo, dos casos puntuales en la línea de lo que se hacía en Europa. En palabras de Roig Castellanos, "hubo un intento frustrado en 1795 de fundar un periódico titulado Diario del Bello Sexo, pero el rey Carlos IV no concedió su aprobación. (...) Otra tentativa infructuosa [fue] la de sacar a la luz Lyceo general del bello sexo, llevada a cabo en 1804 por el presbítero Antonio Marqués (Roig, 1977:10).

Sin embargo, y contra lo que pudiera parecer, la prensa de modas no nace precisamente en revistas especializadas en el tema, sino que cobra fuerza como sección principal de publicaciones de información general que, imitando las tendencias de otros países europeos, llegan muy poco a poco a nuestro país. Es el caso de las women's pages de los diarios anglosajones que, como recoge la profesora Juana Gallego (1990: 
24), ya existían como producto específicamente dirigido a las mujeres, con formato sábana e inlcuidas en el propio cuerpo principal del periódico.

Una prueba de lo que decimos referida al caso español es Diario Mercantil de Cádiz (1802-1837), una publicación de marcado sentido comercial que, muy a principios del XIX, publicaría un suplemento bajo el título de Correo de las Damas donde aparecían ya informaciones sobre modas de París y Londres. "Se publicaba -dice Ma Cruz Seoane (1983: 21)- un Correo de las Damas que, a decir de Alcalá Galiano, era 'de lo más pobre en mérito que en ocasión alguna haya salido de las prensas', que consistía en retazos mal zurcidos de escritos; en su mayor parte, malas traducciones del francés".

Hay que resaltar también, si no nos remitimos al marco geográfico de la Península Ibérica, la existencia de un El Correo de las Damas, editado en La Habana (Cuba) en 1811, con un modelo formal, de contenido y de mercado similar al de la prensa femenina francesa y un origen inmediato en la llamada prensa de "modas y salones”. Destacaba por la riqueza de sus figurines. En cuanto a la educación que propugna para las mujeres, se basaba en orientarla hacia el hogar. Desde sus páginas se reivindica el papel de la mujer como guardiana del hogar.

También debemos apuntar en el mismo sentido el caso de la revista Cartas Españolas (1831-1833) de José María Carnerero. No era una publicación especializada en modas, pero le dedicaba bastantes de sus páginas. Tuvo un éxito considerable y es una de las primeras revistas españolas que se puede considerar como tal por su "intento de modernidad hasta en lo tipográfico" (Gómez Aparicio, 1967: 180). Publicaba figurines con cierta periodicidad y, lo que parece más importante, en dos de las ocasiones estaban impresos en color. La aparición del código cromático en las publicaciones periódicas sí parece ser un éxito de la prensa sobre moda, si bien "lleva a plantearse en qué medida las tintas estándares de impresión utilizadas en los grabados de color condicionaron las elecciones cromáticas por parte de las empresas de tejidos e incluso de la propia clientela" (Pena, 2001: 369).

Pero a pesar de todas estas primeras referencias, no será hasta bien entrado el siglo XIX cuando la mujer se incorpore a la lectura. Lo que supone, según Simón Palmer (2007), que "el mundo editorial trate de atraerla adaptando algunas publicaciones a sus gustos y creando otras específicamente destinadas a ella”. Salvo raras excepciones, podemos concluir que el nacimiento de la prensa especializada en moda es un fenómeno de principios del siglo XIX, al menos en España.

Según Hinojosa Mellado (2005:77) "hay que esperar al siglo XIX para que se introduzca el periodismo destinado a las mujeres, alejado de las preocupaciones políticas y más interesado por asuntos de índole cotidiana”. 
Y aunque, como hemos visto, la prensa diaria solía incluir secciones de modas y poemas dedicados a la instrucción de la mujer, sin embargo, "la mayoría del público femenino adquiere las revistas a él destinadas, que nacen en este siglo y que alcanzarán gran éxito de ventas, y cuya finalidad era principalmente instruir deleitando y hacer cumplir a la mujer adecuadamente su sagrada misión en el mundo" (Simón Palmer, 2007).

\section{La revista especializada}

Una idea que hay que tener presente antes de ahondar en el tema de las revistas de moda en el XIX es la precariedad de este tipo de publicaciones en sus comienzos, con tiradas que no lograban ni la cifra mínima de suscriptores (alrededor de 200) que hubieran permitido subsistir a las empresas. En esa línea podemos hablar de El Periódico de las Damas (que en 1822 es ya una revista especializada), a cuyo editor, don León Amarita, Gómez Aparicio (1967: 143) considera el introductor del periodismo femenino y de modas en España.Y donde, entre otros temas, se publicaban extensas secciones de noticias sobre modas, "que tomaban como modelos a The Ladies Journal y Le Journal des Dames que ya existían de antiguo en Londres y París" (Gómez Aparicio, 1967: 159). Esta publicación es una de las primeras que distribuía todas las semanas con cada ejemplar un figurín en dibujo a pluma y con leyenda en francés, ya que era enviado por un corresponsal desde París. Marcelino Tobajas (1984: 236) puntualiza además que los ejemplares tenían 48 páginas y "los figurines eran de señora y caballero, se repartían a los suscriptores y eran reproducciones de las que publicaba el periódico francés L'Observateur des Modes”. Ma Cruz Seoane (1983: 103) apunta incluso que el figurín estaba coloreado.

La publicación, “que no pasó de un ensayo mediocre de Literatura femenina” (Gómez Aparicio, 1967: 159), sólo vivió 6 meses -25 números-, de enero a junio de 1822 e incluía también un comentario político en cada número, bien en torno a la sesión de Cortes, bien a una explicación de algún aspecto relacionado con la Constitución. Parte importantísima era la sección de 'Modas' ilustrada con el figurín.

En casi todos sus números incluyó una sección llamada 'Cartas de una madre a su hija que va a contraer matrimonio’ con consejos detallados sobre la decoración del hogar, el gobierno de la casa, el arreglo personal de la esposa, cómo tratar al marido o sobre las ventajas de dormir en cuartos separados frente a la nueva moda que se estaba extendiendo de poner los lechos en la misma estancia. En palabras del editor de esta publicación en su número 1, "el propósito de esta revista era educar a la mujer para el matrimonio, ya que era éste el estado natural de la mujer”. También se incluían las 'charadas' cuyas respuestas enviaban las lectoras demostrando que también las mujeres eran inteligentes. 
Los elementos icónicos en este tipo de revistas ilustradas eran fundamentales dado el grado de analfabetismo de la población española de entonces, mayor entre las mujeres, de ahí la importancia de los figurines que aparecían con el grado máximo de representación, con toda la precariedad técnica que queramos encontrarle. "Las revistas -dice Pena, (2001: 366)- enseñaron a las mujeres a leer grabados, a considerar las modas según sus trazos, a pensarla en blanco y negro...”. El autor considera el figurín como agente morfológico de lo que representa: el traje. Y dice que aunque pueda ofrecernos una idea general del corte del vestido (...) no puede devolvernos el calor ni el tacto de la prenda y que el obligado cambio de escala imposibilita la reproducción de detalles importantes. Y concluye que esta incompetencia para traducir lo sutil hace que en los códigos empleados prime lo estructural y volumétrico, lo que da a entender que la moda descansa sobre variaciones estructurales antes que sobre ciertos detalles.

Un estudio de 1803 daba para España un índice de analfabetismo alrededor del 90 por ciento, cifra que en torno a 1860 se redujo al 75 por cientoํㅜㄹ lo que seguía siendo altísimo si lo comparamos con países vecinos como Francia donde para el mismo periodo se contemplaba una tasa del 32 por ciento de analfabetos. Si a ello sumamos que el salario medio de una trabajadora no superaba los cuatro reales diarios, es lógico pensar que estas publicaciones dirigidas a las mujeres fueran leídas por una minoría perteneciente a las capas altas de la sociedad.

Casi todas las revistas femeninas del siglo XIX centraban sus páginas en la moda, especialmente en la francesa y la española. La mayoría prefería seguir los cánones marcados por nuestro país vecino pero otras, que eran minoría, buscaban ensalzar los valores nacionales.

Sin embargo, la segunda mitad del siglo XIX verá nacer otro tipo de revistas dedicadas a la mujer: las de carácter feminista. Es lo que Perinat y Marrades (1980) denominan como 'prensa femenina de tendencia feminista o emancipista que reividinca la participación activa de la mujer en diferentes campos'. Son periódicos fundados y dirigidos por mujeres defensoras de los derechos de sus congéneres. Destacaron el caso de Ellas, gaceta del bello sexo (1851) y La Mujer (1851-52), si bien en la primera, dicho carácter va perdiendo fuerza hasta convertirse en una revista de modas. La segunda, La Mujer, despuntaba como un "periódico escrito por una sociedad de señoras y dedicado a su sexo" como rezaba en la misma revista, y que manifestaba también una inquietud por la educación, la moral o el trabajo. Otras publicaciones que también

\footnotetext{
1 Datos de analfabetismo dados por Luis Sánchez Agesta (1990: 507): 1803, sabe leer un 5,96\%; en 1841, 9,21\%; 1860, 19,27\%; 1877, 24,48\%; 1887, 28,49\% y 1900, 33,45\%. En Historia del Constitucionalismo Español. Centro de Estudios Constitucionales de Madrid, 1990. Datos de analfabetismo dados por C.M. Cipolla (1970: 142): "En efecto, en 1857, de una población total de 15.591 .000 habitantes y ciudadanos mayores de diez años de 11.591.000, existía en España un 75\% por ciento de analfabetismo adulto”. En Educación y desarrollo en Occidente. Barcelona: Ariel, 1970.
} 
abordaron el problema de la educación femenina fueron El Tocador (1844-1845), que expresa la necesidad de que la instrucción de las madres les permita ocuparse convenientemente de sus hijos y Gaceta de las mujeres (1845), para cuyas autoras también la educación de la mujer revierte en el bien de sus hijos.

Se diferencian claramente de las revistas femeninas de principio de siglo, un tipo de revistas que iban dirigidas a un público muy reducido de la sociedad femenina, la burguesía. Son revistas sin ideología política o social que, en palabras de Blasina Cantizano (2004: 285), "se dirigen a la mujer tradicional para reforzarle la importancia de su condición de esposa y madre a través del eterno femenino”. Su contenido se basa principalmente en la moda y es por esto que casi todas estas publicaciones adjuntaban figurines para que las "señoritas" de la alta sociedad estuvieran al día de la moda. Los consejos del hogar, cómo cuidar a los hijos, así como los del aspecto físico y el trato al marido, eran otros de los apartados que incluían estas revistas. También publicaban ecos de sociedad y relatos por entregas y dedicaban un pequeño espacio a la literatura, pero siempre con un mismo mensaje, educar a las mujeres para comportarse como damas. Ninguna de estas publicaciones se preocupó por formar intelectualmente a las mujeres, ya que consideraban que lo único que debían aprender era a ser buenas esposas y madres. De este modo, mujeres de distinta procedencia social fueron educadas bajo las mismas premisas de religión, moral y labores domésticas.

\section{Correo de las Damas}

"Ya en 1833 -escribe Ma Cruz Seoane (1983: 136 y 137)-, pero antes de la muerte del rey [Fernando VII], comienza a publicarse el 3 de junio el Correo de las Damas, que duraría, con diversas interrupciones, hasta enero de 1936. Como El Periódico de las Damas, su precedente en el trienio, su objetivo principal eran las informaciones de modas acompañadas de figurines y se dirigía, como aquel, a una clientela acomodada".

El Correo de las Damas en su primer número se definía como "un periódico semanal, ameno, ligero, florido propio en fin de las bellas a quien se consagra (...)". Sánchez Aranda y Barrera del Barrio (1992: 118) lo definen "literariamente opuesto al Romanticismo" pero destacan que en él colaboró asiduamente Larra.

Se dedicaba fundamentalmente a la moda, a la literatura de entretenimiento, facilitaba información sobre teatro y otro tipo de espectáculos. No desestimaba los artículos de opinión sobre la función esencial de las mujeres y se mostraba partidario de una educación más esmerada que le capacitara para ser educadora de sus hijos y sustentar el buen funcionamiento de la sociedad y de la familia.

Ya en su primer número exponía sus intenciones al señalar que "como periódico de modas, las extranjeras y nacionales ocuparán en gran manera nuestra atención (...). En los figurines que daremos perfectamente 
grabados e iluminados, no nos limitaremos a los trajes de hombre o señora: los muebles más en boga, los carruajes, cuantos objetos son del dominio de la instable moda encontrarán en nuestro periódico un lugar que les sea especialmente destinado.

Como periódico de bellas artes, comprenderemos en el dibujo (...) aquellas delicadas labores del bello sexo que con él tienen relación (...). Bajo el título de Amena Literatura comprenderemos artículos ligeros y burlones de costumbres, anécdotas picantes, cuentos cortos, alguna brevísima composición poética (...) y juicios de aquellas otras que por su amenidad son de más gusto de las señoras".

El Correo de las Damas tenía una serie de secciones fijas y otras variables. Dentro del primer grupo se encuentra 'Amena Literatura', que siempre ocupaba las tres primeras páginas de cada ejemplar. Le seguía 'Modas', que explicaba con detalle los figurines de cada entrega y decía lo que estaba de moda en países como Francia e Italia. Por último, 'Noticias varias', donde tenían cabida todo tipo de informaciones.

Dentro del segundo grupo, las secciones se van introduciendo según la época del año, como ‘Toros’ o ‘Teatro'. La sección de 'Avisos Interesantes' o la de 'Rehiletes' (que solía contar chistes) aparecen sólo en determinados ejemplares y son de las más curiosas. Otras secciones son 'Anécdotas', 'Precauciones y Remedios'. La primera aparece en casi todos los números y en ella suelen narrarse anécdotas sucedidas en la historia que tienen como protagonistas a personajes de la realeza. En el caso de 'Precauciones y Remedios' se recomienda a las jóvenes esposas trucos para la mejor limpieza del vestido o sobre su cuidado físico.

\subsection{Diseño}

El Correo de las Damas tenía un formato de 150 x 220 mm. Salía todos los miércoles y cada número constaba de ocho páginas de "buen papel y esmerada impresion" tal y como se recogía en el prospecto de presentación que acompañó al primer ejemplar. Su diseño era tributario del libro. Cada ejemplar se acompañaba de seis ilustraciones: tres figurines de señora, uno de señores, uno de prendidos y otro de dibujos variados (complementos tales como sombreros, chales y peinados de la época). Cada trimestre se entregaba también, a modo de suplemento, cuatro estampas más de trajes regionales, vestidos de niños, carruajes o muebles.

Todos estos grabados eran de excelente calidad y aparecían con el pie 'Modas de París' y en las páginas siguientes se explicaban los figurines con todo detalle: el color que tenía cada uno de ellos, el tipo de tela, los complementos que se podían añadir, etc. Casi todas estas ideas provenían de dos revistas francesas: Petit Courier y Journal des Dames et des Modes. 
En la última página del primer número, en la sección 'Variedades', se incluye una información titulada "Explicación del figurín” en la que se dice lo siguiente: "deseosos de mejorar en los posible nuestros figurines, y viendo que en nuestros grabadores no hay las disposiciones suficientes para darnos las laminas en poco tiempo y al módico precio que exije un periódico, hemos apelado por vía de ensayo a la litografía, y no descontentos enteramente del primer paso esperamos satisfacer bien pronto de todo punto los deseos de nuestras suscriptoras", lo que prueba la gran importancia que daban a estas imágenes.

Su precio en Madrid era de 14 reales al mes "llevado a las casas", pero si se compraban ejemplares sueltos el precio era de 5 reales; en las provincias costaba 50 reales por trimestre, "franco de porte".

En cuanto a la disposición de los artículos, estos se presentaban en dos columnas, con o sin corondel visto, y justificados, en letra romana antigua. Para diferenciar el cambio de sección se disponía una orla debajo del título, el cual iba en letra gótica, sombreada en muchos casos.

En lo que a portada y contraportada se refiere, su puesta en página fue prácticamente idéntica durante los tres años de vida de la revista. En 1883, salvo los tres números últimos, encabezaba la portada un grabado de un querubín esparciendo flores, por debajo del folio donde se incluía el número de ejemplar, el año y la fecha. A continuación se disponía una caña y bajo ésta el grabado y tras éste se situaba la cabecera en dos líneas: en la primera aparecía la palabra 'Correo' en letra hueca, sombreada, versales y romana antigua y en la segunda 'De las Damas' en letra gótica y a mayor cuerpo. A finales de 1833, este grabado es sustituido por otro en el que aparece un ángel montado sobre un perro pequeño con un arco en una mano y un sobre cerrado en la otra. El lema que había aparecido hasta el momento 'Las bellas gustan de ligereza y variedad' es sustituido por el de 'Periódico de modas, bellas artes, amena literatura, música, teatros, etc.'. No obstante, en 1834 vuelve al grabado inicial tras probar con otro ángel con flechas para, finalmente, suprimirlo en 1835.

En ocasiones, la portada iba acompaña por una orla a modo de recuadro que realzaba los contenidos, si bien en 1835 ésta desaparece para dar más limpieza a la puesta en página. Finalmente, en diciembre de ese mismo año, la revista edita su último número viéndose obligada al cierre por la falta de ventas y suscriptores.

\section{La Moda elegante ilustrada}

Esta revista tiene sus orígenes en 1842. Su antecedente fue un pequeño periódico femenino titulado $\mathrm{La}$ Moda que empezó a publicarse en Cádiz en 1841, de la mano de don Francisco Flores Arenas, escritor an- 
daluz y periodista conservador de El Globo. Unos años más tarde, en 1849, el editor don Abelardo de Carlos compra este pequeño periódico de modas, entonces en crisis, y lo convierte en una publicación de gran éxito y con beneficios.

"De aquel periódico -comenta Miguel B. Márquez (2006) - que se sostenía con dificultad, hizo don Abelardo al adquirirle un periódico de gran tamaño, con grabados en negro y mejoras contínuas, hoy conocido en todos los países con el nombre de La Moda elegante e ilustrada, como unos de los mejores en su género. No le arrendaron las pérdidas de aquella empresa, que calificaban algunos de ruinosa, y hoy es una de las más lucrativas que ha conseguido en España el periodismo".

"La revista pertenecía a la misma empresa que La Ilustración española y americana hasta 1914, fecha en que ésta fue vendida a Rafael Picabea. Por su larga vida es muy interesante, no sólo para seguir la evolución de la moda, sino también como información sobre la vida cotidiana de las mujeres acomodadas" (Seoane y Sáiz, 1996: 190).

Tuvo tanto éxito que se vendió por toda España. En 1861 cambió su formato y adoptó el nombre de La Moda elegante ilustrada y a partir de 1871 comienza a publicarse también en Madrid. La revista se siguió publicando hasta 1927. En palabras de Ma Cruz Seoane y Ma Dolores Sáiz (1996: 190) "se había comenzado a publicar en Cádiz en enero de 1842 con el título La Moda, y que al trasladarse a Madrid se llamó en 1861 La Moda elegante, y más tarde La Moda elegante e ilustrada; a partir de 1912 nuevamente La Moda elegante, añadiendo más tarde el adjetivo ilustrada".

Al precio de dos reales la revista se vendía semanalmente; no obstante, este precio variaba en función del lugar de venta. Por ejemplo, en España, la suscripción de lujo (con figurines y patrones) durante un año costaba 160 reales, 80 reales si eran seis meses, 45 si eran tres meses y 12 si se trataba de una suscripción al mes. En Cuba y Puerto Rico, el coste para un año eran 12 pesos fuertes y para seis meses, 7 . Cuando se establece la peseta como moneda, el precio en España, Canarias y Portugal estaba entre 1,50 pesetas al mes y 40 pesetas al año. Además, a las suscriptoras se les hacía una rebaja del 25\% en la compra de La Ilustración española y americana, la otra revista editada por don Abelardo de Carlos.

Hasta 1855 la revista se compondrá de cuatro páginas, con un diseño muy similar al de un libro: sólo aparecía texto y no había ningún tipo de imagen. Los únicos recursos de diseño eran los distintos elementos tipográficos empleados como elementos de ordenación, es decir, filetes, plecas, lutos u orlas. Y la variedad formal se conseguía, además de con estos elementos, empleando distintas familias, cuerpos y estilos tipográficos en los titulares. 
En la década de los sesenta se incrementa el número de secciones con lo que se alcanzan las ocho páginas. Ya en 1922 la revista se convierte en mensual y tendrá 28 páginas, para volver a disminuir su periodicidad en 1927 tornándose quincenal hasta su desaparición en diciembre de este mismo año.

Conforme avanza el siglo, esta revista va cambiando su aspecto formal, gráfico y tipográfico, pero también sus contenidos, adquiriendo una estructura cada vez más estable. El número de secciones vinculadas a la moda se iba incrementando y también el de los grabados (sobre trajes y vestidos, punto de cruz e, incluso, a partir de 1870 se incorporan imágenes de mobiliario y decoración de interiores). Todos estos contenidos se acompañan de figurines y suplementos que aportarán a las suscriptoras patrones de los vestidos que están de moda. Para P. Pena fueron "los defectos de las revistas de moda los que decidieron el 'qué' de la moda, el sentido de ésta y, al hacerlo, se convierten en agentes morfológicos: conducen hacia una futura moda estructuralista, más centrada en las líneas generales, en las yuxtaposiciones del corte, que en lo táctil y lo pequeño. La moda es, entonces, lo reproducible a escala de figurín" (Pena, 2001: 367).

Desde su aparición y hasta 1855 la revista mantendrá tres secciones fijas: ‘Costumbres', ‘Teatro’ y ‘Literatura'. La sección sobre 'Moda' no aparece en todos sus números, algo contradictorio si tenemos en cuenta el nombre de la revista. Al principio recibía el nombre de 'Modas', después 'Ecos de Moda' y, al final, 'Revistas de Modas'. Esta sección estaba integrada generalmente por un artículo y noticias relacionadas con las últimas tendencias en telas, abalorios, los modelos de trajes o corpiños que se llevarán y más tarde incorporará los figurines.

A partir de 1867 el contenido cambia debido a que la tecnología permitía ya a través del fotograbado la posibilidad de incluir grabados en sus páginas. De esta manera, los contenidos eran más amenos y se explicaban con más claridad. Desde este momento, la mitad de la revista estuvo dedicada a la elaboración de bordados, punto de cruz, trajes, complementos, decoración de interiores, muebles y adornos para el hogar.

Desde los años 60 la revista queda dividida en dos grandes bloques separados por una imagen a doble página que ocupaba la mitad de la revista. En la primera, se daban las informaciones relativas a 'Moda y Hogar' y, en la segunda, la parte más literaria, incluyendo los artículos sobre costumbres, poesías, fragmentos de novelas u obras teatrales y otros contenidos relacionados con la cultura y el ocio.

A finales de esa misma década se empiezan a introducir las primeras ilustraciones. Desde su aparición hasta este momento las páginas de esta revista no llevaban más que textos pero, a partir de 1860, las imágenes empiezan a ganar terreno al texto. La incorporación de los grabados implicó un cambio importante tanto en 
los contenidos como en el aspecto formal y diseño. En lo que a los contenidos se refiere, se amplía la sección de moda que antes incluía un único artículo al final y, desde este momento, ocupará las cuatro o cinco primeras páginas además de la portada. Por otro lado, los grabados adquieren una primacía fundamental tanto por su función decorativa como por su capacidad para transmitir información. El texto pasa a estar subordinado a las imágenes, que condicionan el diseño de la página.

\subsection{Diseño}

Esta revista nace, como muchas publicaciones de la época, con una imagen muy similar a la de los libros. "La revista sólo se distinguía del libro por su portada endeble y flexible; los titulares se parecían a los encabezamientos de los capítulos, la disposición de la tipografía era simétrica; el texto se desarrollaba de arriba abajo en columnas sencillas o dobles, a la manera de un libro" (Owen, 1991: 12).

El número de páginas de esta publicación aumentará con el paso de los años. Inicialmente, constaba de cuatro páginas, si bien sólo se imprimían tres, al igual que muchos diarios de la época que "constaban de cuatro páginas y, con frecuencia, únicamente estaban impresas tres de ellas" (Martín Aguado y ArmentiaVizuete, 1995: 139) y el texto se distribuía en dos columnas, separadas por un filete fino y sin ningún tipo de imagen.

Hacia los años 60, con a la aparición de nuevas secciones y la inserción de los grabados, la revista pasará a cuatro páginas. Al mismo tiempo, los contenidos empezarán a distribuirse en tres columnas, separadas también por filetes finos alejándose de la apariencia inicial similar a un libro. Además, no siempre las columnas mantenían un ancho uniforme dado que, si la imagen insertada en el texto tenía la suficiente fuerza, el texto se adaptaba a ella provocando la ruptura de la estructura inicial.

En la década de los 90 habrá un cambio importante que es la desaparición de los corondeles vistos -se suprimen los filetes entre columnas- quedando así el corondel ciego que aporta más blanco a la página y mejora su legibilidad.

\subsection{Portada y contraportada}

A lo largo de la vida de esta revista son las dos páginas que más modificaciones presentan. La portada parte de un esquema muy sencillo en el que destaca la cabecera que, entre 1842 y 1855 cambió cinco veces de diseño. En los años siguientes la portada intercalará texto e imágenes en distintas proporciones según el número. 
En cuanto a la contraportada, hasta 1867 no presentará un diseño propio. Hasta ese momento mantuvo un aspecto formal similar al del resto de páginas interiores. A partir de dicha fecha incorporará nuevos contenidos como pasatiempos, jeroglíficos, imágenes e, incluso, publicidad, hasta que se convierta exclusivamente en una página con anuncios.

\subsection{Cabecera}

Capítulo aparte merecer la cabecera. La primera cabecera que presenta la revista, entre octubre de 1842 y junio de 1843, se caracteriza porque presenta una tipografía gótica, hueca, al ancho de la página y ligeramente curvada, bajo la cual se incluía un filete de tipo fantasía. La segunda, entre junio de 1843 y mayo de 1847, era una cabecera más limpia, con una tipografía más pequeña, en negrita, romana moderna y que incorporaba orejas.

La renovación de 1847 consistió sobre todo, en la incorporación de una tipografía más contundente, egipcia, con rebordes, muy del gusto de la época.

En 1849 hay un nuevo cambio. Sigue siendo una tipografía egipcia, en negrita y versales pero se limpia mucho más la cabecera alejándose del estilo recargado de los primeros años.

En 1855 hay una nueva modificación, se mantiene la tipografía egipcia, negrita y versales pero aparecerá muy condensada. En 1867 hay otro cambio consistente en que desde ese momento la cabecera ocupará mucho más espacio y será mucho más recargada, ornamentada y compleja incorporando una especie de friso sobre el que se dispone la cabecera ondulada con el nuevo nombre La Moda elegante y subtítulo 'El Periódico de las familias'. Desde este momento la revista pasa a definirse como periódico y ya no se destinará sólo a la mujer sino a la familia. Cuatro años más tarde volverá a definirse como 'Periódico de señoras y señoritas'.

En 1893 y 1927 vuelve a modificarse la cabecera siendo esta última modificación la que acompañará a la revista hasta su cierre definitivo.

\subsection{Imágenes y color}

"Los grabados encontraron en periódicos y, sobre todo, en las revistas su principal medio de expresión. Hasta el desarrollo del fotograbado que va a permitir la reproducción de las fotografías -técnica que aparecerá a finales del XIX- los grabados o dibujos impresos cumplen la función de ilustrar los textos de las publicaciones periódicas" (Martín Aguado y Armentia Vizuete, 1995: 185).

$64 \mid n^{\circ} 8$ | doxa.comunicación 
En sus orígenes, La Moda sólo presentaba texto; sin embargo, a finales de los 60 empezó a incluir las primeras ilustraciones ocupando gran parte de la superficie de la página. El tipo de ilustración predominante era el grabado por línea realizado con la técnica del aguafuerte o con instrumentos como el buril. Eran ilustraciones monocromas con un alto contraste entre blancos y negros.

En cuanto a la temática de las ilustraciones, siempre estaban relacionadas con la mujer, predominaban los bordados y puntos de cruz, el mobiliario para el hogar, los trajes y complementos para distintas ocasiones e, incluso, peinados. La puesta en página de estas ilustraciones era muy variada: en ocasiones, a página completa e, incluso, las dos centrales; otras veces, insertadas en el texto con éste fluyendo a su alrededor generando formas caprichosas. También era frecuente el empleo de siluetas y pisados.

Desde el punto de vista del diseño, los grabados adquieren una gran importancia tanto por su función decorativa como por su capacidad para transmitir información. Desde ese momento, el texto estará subordinado a las imágenes, las cuales mejoran el aspecto formal de la revista, atraen la atención del lector y permiten entender mejor la información que se ofrece. Como dice Javier Galán “la irrupción de estos elementos gráficos en las páginas de las publicaciones periódicas tienen dos consecuencias claras. Por una parte, se convierten en un elemento visual importantísimo en la construcción de las páginas y, además, ofrece la posibilidad al periodista de informar a los lectores con una herramienta gráfica" (Galán, 2001: 212).

Con el paso del tiempo, los grabados también llegan a la contraportada, lo hacen de la mano de los anunciantes que acompañan los productos publicitados con imágenes sencillas que capten mejor la atención de posibles compradores.

Poco a poco, el grabado fue siendo sustituido por el fotograbado de medio tono, que agilizaba el proceso de manera considerable y ya, hacia 1890, se incorporaron a la revista de manera evidente las fotografías. En palabras de Enric Satué "la revolución fotográfica se afianzó contra la voluntad de muchos editores de revistas de la época que nunca llegaron a comprenderla” (Satué, 1997: 199).

\subsection{Otros recursos tipográficos}

El hecho de que no se emplearan grabados hasta 1867 hizo que se buscaran otras fórmulas que sirvieran como elementos decorativos y aliviaran la monotonía del texto. Destacó el empleo de filetes y plecas para dar mayor dinamismo a la página y hacer más atractivos los contenidos. En el caso de los filetes dominaban las fantasías y las medias cañas, presentes en la cabecera, incluso serpentinas en alguna ocasión. En cuanto a las plecas predominaron las sencillas aunque también se emplearon modelos orlados. 
A partir de los 80 se introducen las capitulares. Las primeras eran orladas, con adornos florales muy abigarrados. Posteriormente, se fueron simplificando hasta llegar al uso de capitulares ordinarias. También era frecuente el empleo de cenefas o marcos muy orlados que recuadraban epígrafes, titulares o informaciones completas.

\section{Conclusiones}

El siglo XIX vió nacer dos tipos de revistas dedicadas a la mujer: las consideradas propiamente femeninas y las de carácter feminista. Dentro del primer grupo hubo una serie de características que las agrupaba y diferenciaba de las segundas. Se trató de un tipo de revistas que iban dirigidas a la burguesía. Su contenido se basaba principalmente en la moda y es por esto que casi todas estas publicaciones adjuntaban figurines para que las "señoritas" de la alta sociedad estuvieran al día de la moda. Los consejos acerca de cómo cuidar a los hijos, así como los del aspecto físico y el trato al marido, eran otros de los apartados que incluían estas revistas. Además, se dedicaba un pequeño espacio a la literatura, pero siempre con un mismo mensaje: educar a las mujeres para comportarse como damas. Ninguna de estas publicaciones del primer grupo se preocupó por formar intelectualmente a las mujeres, ya que consideraban que lo único que debían aprender era a ser buenas esposas y madres. El diseño de estas revistas de moda del siglo XIX era un diseño limpio y elegante que se correspondía con todos aquellos valores que querían inculcar a la mujer: el cuidado de la familia, la integridad, la discreción, el saber estar o los buenos modales.

Por otro lado, la prensa de carácter feminista se desarrolló, sobre todo, en la segunda mitad del siglo XIX. Fueron publicaciones fundadas y dirigidas por mujeres defensoras de los derechos de sus congéneres.

Desde el punto de vista formal se trataba de publicaciones con un diseño heredado de los libros. Poco a poco empezarían a imitar a los periódicos de la época para, finalmente, y al hilo de los nuevos avances tecnológicos, adoptar un estilo propio. En palabras de W. Owen, "la historia del diseño de revistas es la lucha por apartarse de la tipografía tradicional de los libros y diarios, y por crear una nueva síntesis de texto y fotografía" (Owen, 1991: 12). Si bien en sus orígenes su diseño era como el de los libros, fue adoptando poco a poco formas propias de los periódicos para, finalmente, adquirir una imagen propia, característica, pero esto no será hasta ya entrado el siglo XX coincidiendo con la llegada de las vanguardias artísticas.

Después del análisis formal de La Moda elegante y Correo de las Damas se puede hablar de una estética de la prensa femenina de moda del siglo XIX. Ésta se concreta en un formato pequeño, similar al de los libros, escaso número de páginas -entre cuatro y ocho-, escasa presencia de imágenes sólo representadas a través 
de los figurines, utilización de filetes y orlas como elementos de ordenación, separación y a modo de recuadros, tipografías romanas clásicas en los elementos textuales y góticas en las cabeceras, disposición del texto en dos o tres columnas justificadas, etc.

Al igual que muchas revistas actuales (Telva, Elle, AR, Marie Claire, Woman, etc.), la mayoría de las publicaciones del siglo XIX dirigidas a la mujer dedicaban sus páginas a ofrecer apuntes de cómo vestirse, belleza, trucos del hogar, consejos para destacar, normas de conducta, decoración, etc. Las únicas diferencias que se establecen entre estas publicaciones y las de ahora es que, actualmente, se incluyen secciones sobre tema laboral, psicología, derecho, etc., y que también se puede hablar del cuerpo femenino o el sexo sin tapujos (Cantizano, 2004: 289).

En definitiva, y como señala esta misma autora, "la prensa dirigida a la mujer poco ha evolucionado desde que aparecieran las primeras publicaciones aquí repasadas, cuestiones como belleza, éxito social, hogar o modas siguen ocupando una sección fija en las publicaciones del siglo XXI, lo que nos plantea si el papel de la mujer en la sociedad ha evolucionado realmente o sigue anclado a la tradición" (Cantizano, 2004: 297).

\section{ANEXO. Imágenes de El Correo de las Damas y La Moda elegante}

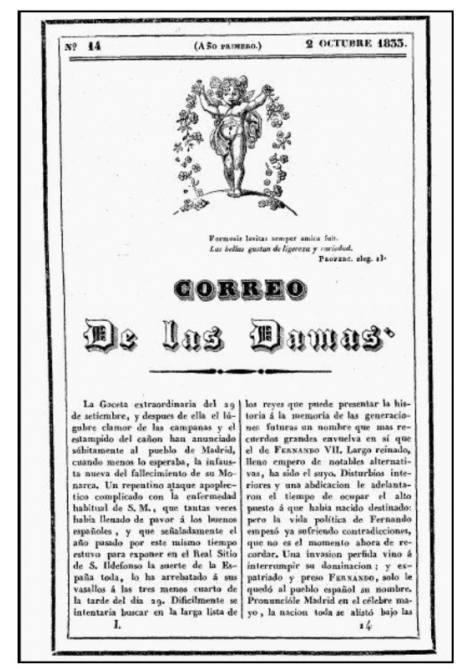

2 de octubre 1833 (portada).

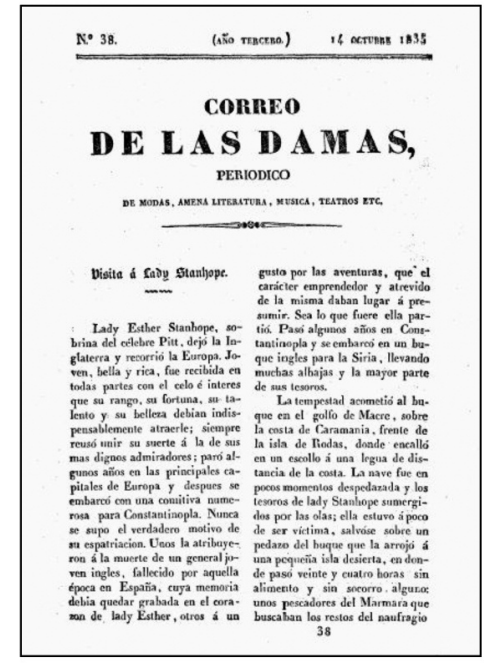

14 de octubre 1835 (portada).

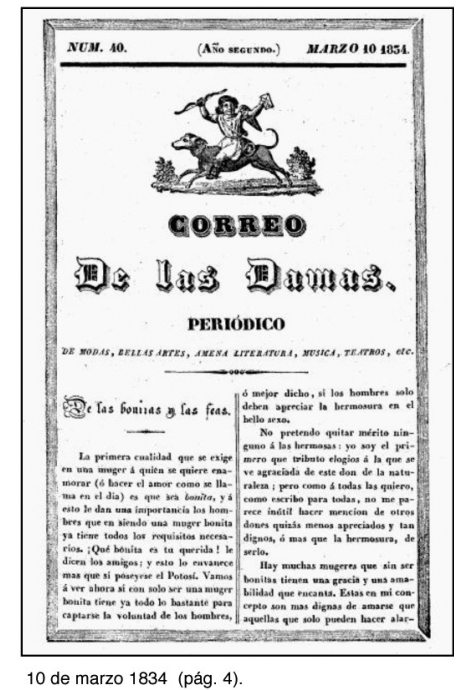

10 de marzo 1834 (pág. 4). 


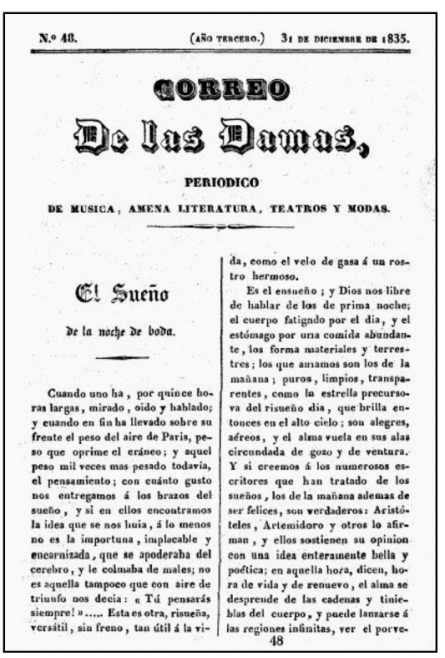

31 de diciembre de 1835 (portada).

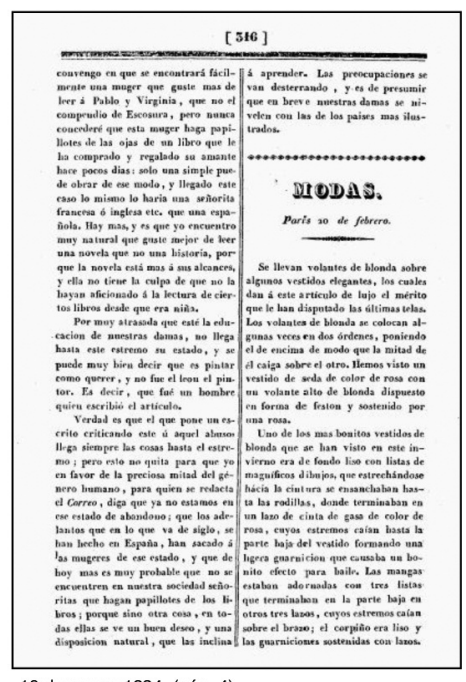

10 de marzo 1834 (pág. 4).

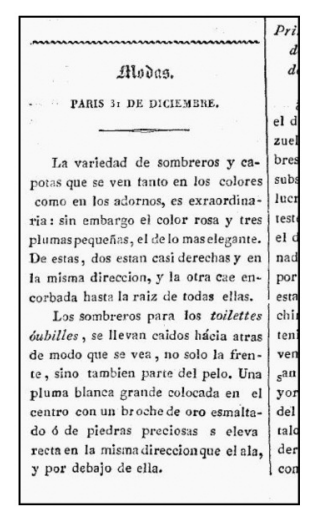

15 de enero 1834 (pág. 8)

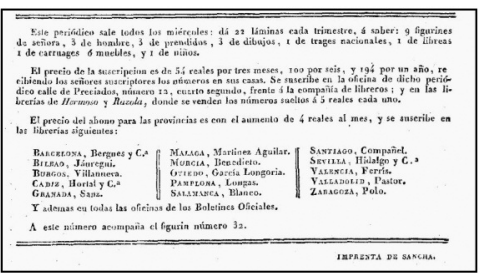

13 de noviembre 1833 (pág. 10).

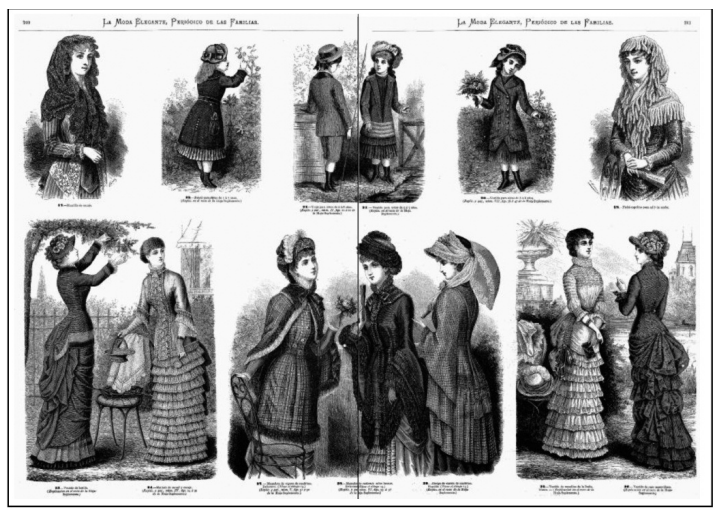

6 de septiembre 1881 (páginas centrales).

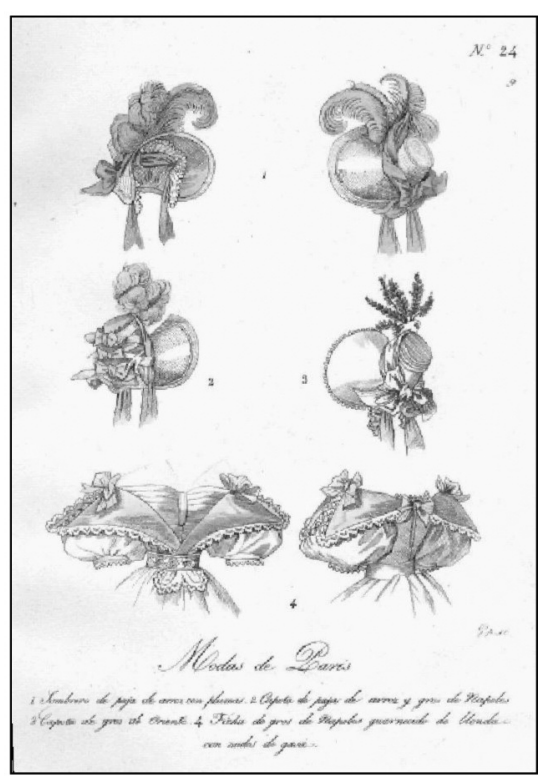

2 de octubre 1833 (pág.7)

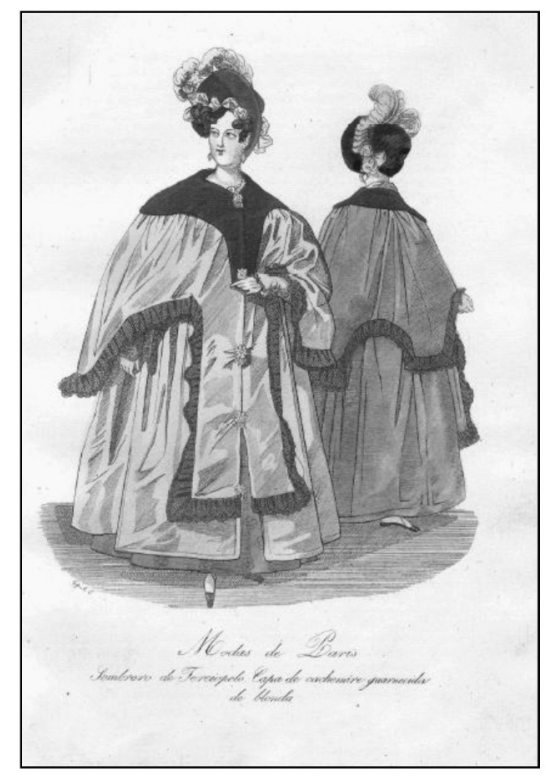

13 noviembre 1833 (pág. 5)

$68\left|n^{\circ} 8\right|$ doxa.comunicación 


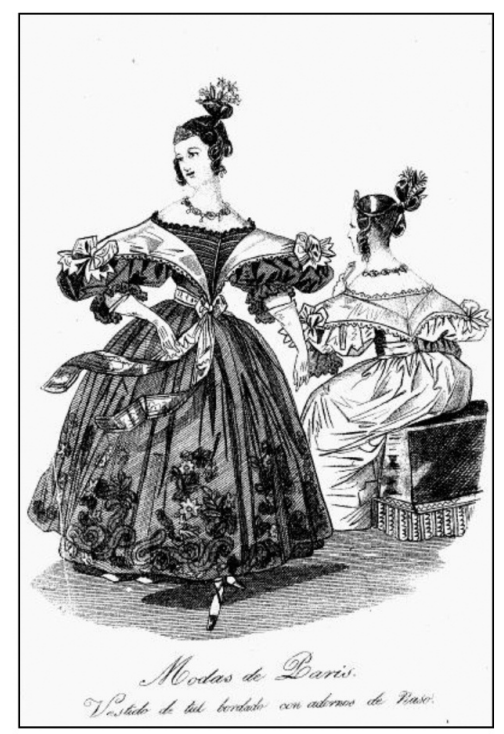

15 enero 1834 (pág. 5)

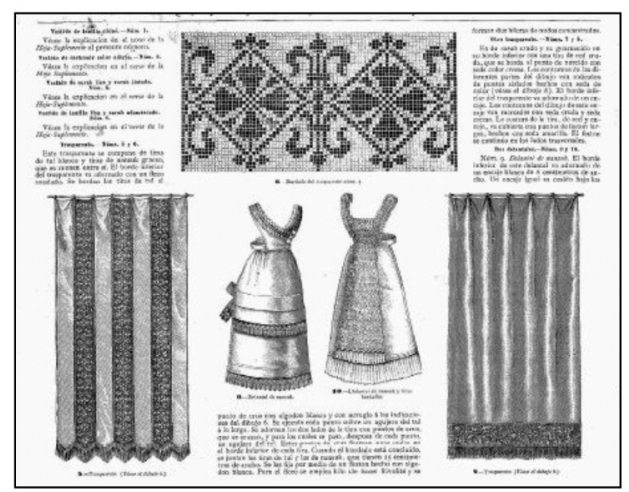

Septiembre 1881 (pág.2)

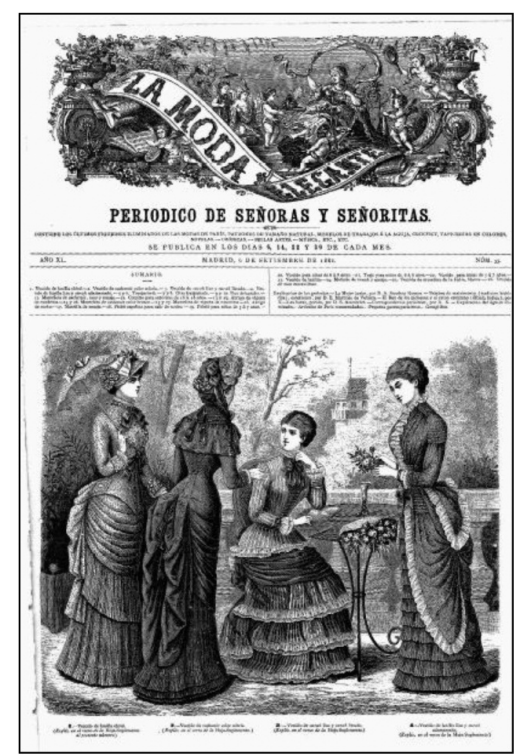

6 de septiembre 1881.

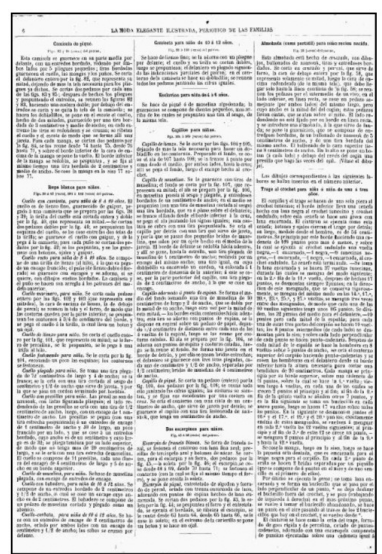

Enero de 1869 (pág.6).

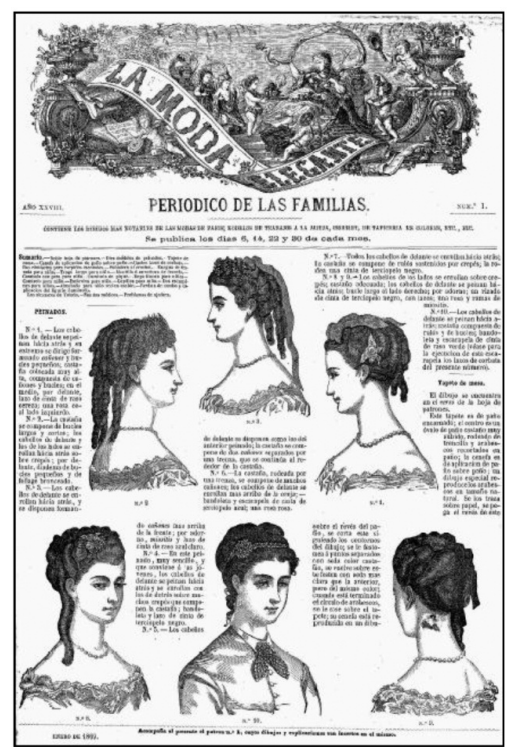

Enero de 1869 (portada).

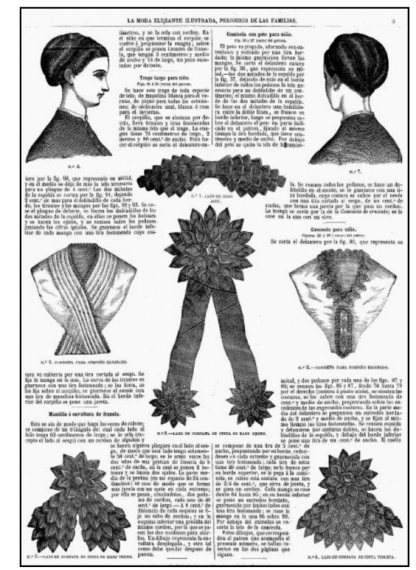

Enero de 1869 (pág.3)
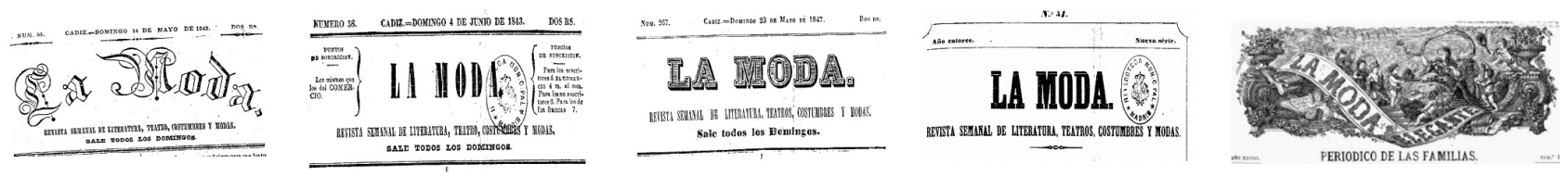


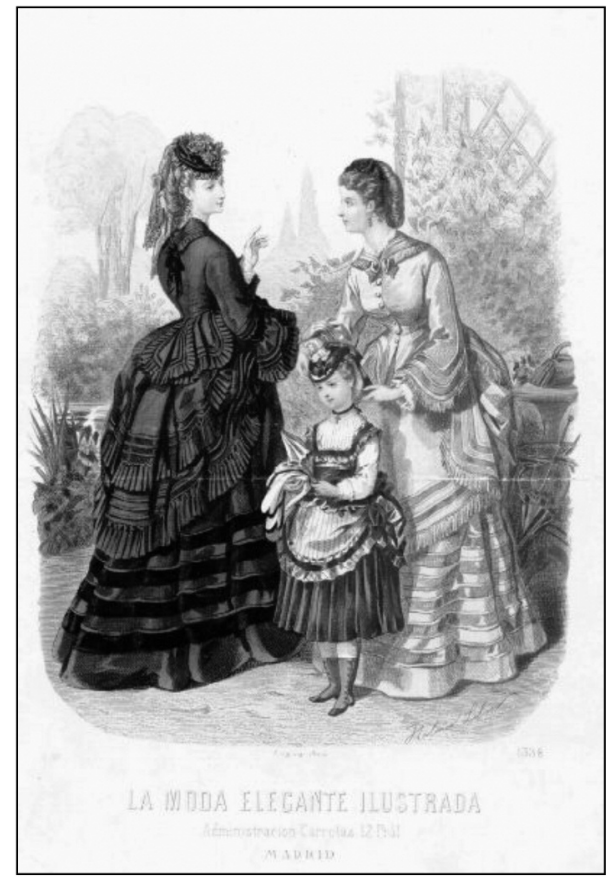

6 de enero de 1873 (pág.15)

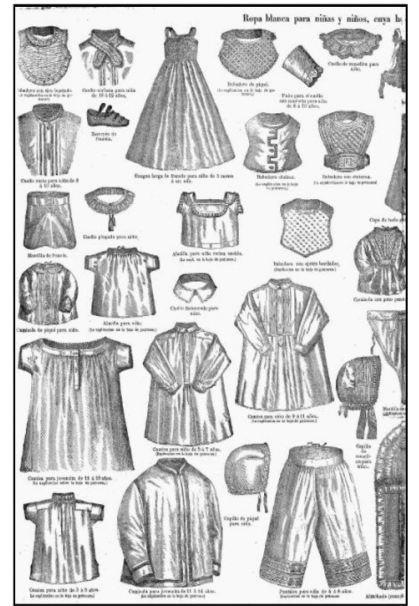

Enero de 1869 (pág.4).

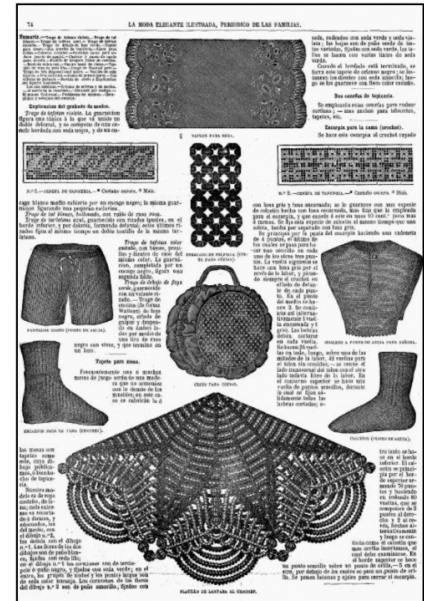

Marzo de 1869 (pág.2).

\section{Referencias bibliográficas}

Cantizano Márquez, B. (2004): “La mujer en la prensa femenina del XIX”, en Ámbitos, no 11-12. pp. 281-298.

Diezhandino Nieto, Ma P. (1988): “La especialización en los medios impresos: Evolución y perspectivas” en V.V.A.A: La prensa ante el cambio de siglo. Bilbao: Deusto.

Galán, J. (2001): “Aprender a ver los diarios: elementos visuales en la composición de las publicaciones periódicas”, Litterae, vol.1. pp. 212-213.

Gallego, J. (1990): Mujeres de papel, de Hola a Vogue: la prensa femenina en la actualidad. Barcelona: Icaria. pp. 24-25.

Gómez Aparicio, P. (1967): Historia del Periodismo Español. Desde la 'Gaceta de Madrid' (1661) hasta el destronamiento de Isabel II. Madrid: Editorial Nacional.

Hinojosa Mellado, M. P. (2005): La persuasión en la prensa femenina: análisis de las modalidades de la enunciación. Murcia: Universidad de Murcia.

Jiménez Morell, I. (1992): La prensa femenina en España (desde sus orígenes a 1868). Madrid: Ediciones de la Torre. 
König, R. (2002): La moda en el proceso de civilización. Valencia: Engloba.

Lipovetsky, G. (1998): El imperio de lo efimero: la moda y su destino en las sociedades modernas. Barcelona: Anagrama.

Márquez, Miguel B.: “D. Abelardo de Carlos y La Ilustración Española y Americana”. Disponible en http://www.us.es/ grehcco/ambitos13-14/11mbmarquez.pdf. (Recuperado el 12.04.2006)

Martin Aguado, J. A. y J. I. Armentia Vizuete (1995): Tecnología de la información escrita. Madrid: Editorial Síntesis.

Owen, W. (1991): Diseño de revistas. Barcelona: Gustavo Gili.

Paricio, P. (1998): Una aproximación a las dimensiones comunicativas de la moda: análisis de la comunicación de la moda en la prensa de información general española durante el s.XX. Madrid: Universidad Complutense de Madrid.

-(2000): "El encuadre de la moda en los diarios españoles de información general de ámbito nacional”, Revista Latina de Comunicación social, 28. Disponible en http://www.ull.es/publicaciones/latina/aa2000sab/119paricio.html (Recuperado el 22.02.2008).

Pena, P. (2001).: "Análisis semiológico de la revista de modas romántica”, Estudios sobre el Mensaje Periodístico, nº 7.

Perinat, A. y Marradés, M. I. (1980): Mujer prensa y sociedad en España 1800-1939. Madrid. Centro de Investigaciones Sociológicas.

Roig Castellanos, M. (1977): La mujer y la prensa. Madrid: Tordesillas.

- (1989): La mujer en la historia a través de la prensa, Madrid: Ministerio de Asuntos Sociales.

Sánchez Aranda, J. J. y Barrera Del Barrio, C. (1992): Historia del Periodismo Español. Desde sus orígenes hasta 1975. Pamplona: EUNSA.

Sánchez Agesta, L. (1990): Historia del Constitucionalismo Español. Madrid: Centro de Estudios Constitucionales de Madrid.

Satué, E. (1997): El Diseño gráfico en España: historia de una forma comunicativa nueva. Madrid: Alianza Forma.

Seoane, M. C. (1983): Historia del periodismo en España. 2. El siglo XIX. Madrid: Alianza Universidad Textos.

Seoane, M. C., y Saiz, M. D. (1996): Historia del periodismo en España. 3. El siglo XX: 1898-1936. Madrid: Alianza Editorial.

- (2007): Cuatro siglos de periodismo en España, de los “avisos" a los periódicos digitales. Madrid: Alianza Editorial.

Simón Palmer, M.C.: "La mujer lectora", Fundación Germán Sánchez Ruipérez. Disponible en: http//:www.fundaciongsr.es/documentos/boletin9/5.htm (Recuperado el 19.09.2007).

Smith, A. (1979): The Newspaper. An Internacional History. London: Thames and Hudson.

Tobajas, M. (1984): El periodismo español. Madrid: Forja Comunicación. 
